Original Research Paper

\title{
Biomimetic and Evolutionary Design Driven Innovation in Sustainable Products Development
}

\author{
${ }^{1}$ Raffaella Aversa, ${ }^{2}$ Relly Victoria V. Petrescu, ${ }^{2}$ Florian Ion T. Petrescu and ${ }^{1}$ Antonio Apicella \\ ${ }^{1}$ Advanced Material Lab, DADI Polytechnic School, Second University of Naples, Aversa (CE), Italy \\ ${ }^{2}$ ARoTMM-IFToMM, Bucharest Polytechnic University, Bucharest, (CE) Romania
}

Article history

Received: 19-11-2016

Revised: 22-11-2016

Accepted: 23-11-2016

Corresponding Author: Apicella Antonio

Advanced Material Lab, DADI

Polytechnic School, Second

University of Naples, Aversa

(CE) Italy

Email: antonio.apicella@unina2.it

\begin{abstract}
An innovative, design-driven, sustainable approach in conceiving, developing, producing, using new materials can be effective in strengthening the competiveness and success of creative industries linked to manufacturing (e.g., biomedical, architecture, automotive, art, crafts, supports for cultural items, decoration, fashion, furniture, lighting, interior design materials and products, jewels, luxury, media supports, publishing, sport and toys), adding value to products and processes also by 'immaterial' factors (e.g., trend translation, enhanced sensations, values). The vision that the research and the advancement of scientific and technological knowledge can be driven by the needs of sustainable development of products and goods has been revived as a strategy for sustainable development. In the evolutionary Design process, creativity determines the mutation of an object shape (material or structure morphology) and this triggers an evolutionary design that repeatedly involves technological development of material, shape and structure. A Biomedical product evolutionary design case study based on these principles has been specifically addressed to the dissemination and spreading of innovative material and technology greener solutions. The use of the evolutionary design in the creative medical industry sectors, while adopting sustainable and socially responsible approach to reduce energy consumption and environmental impact conveys a holistic view of the industrial design process in the field of biomedical application.
\end{abstract}

Keywords: Biomimetic, Creativity, Evolutionary Design, Sustainable Development, Innovation

\section{Introduction}

The Authors coordinated research brings together relevant activities from different challenges (health and wellbeing and raw material resource efficiency) and multi-KET (key enabling technologies such as advanced materials and biotechnology) leading the proposed design and fabrication technologies to industrial readiness and maturity for the commercialisation of innovative biomimetic systems while facing societal challenges with high potential for sustainable competitiveness, innovation and growth.

Innovation means focussing creativity in order to invent better or new products, equipment or consumer services, increasing the value returned from invested capital. Today, manufacturers are aware that innovation and creativity are key factors in unlocking potential development and growth.

Thus was born the need for the development of design professionals who know how to face and manage the increasing amount of technological innovation that scientific research offers us today. Already in the years 20-30 László Moholy-Nagy addressed the problematic relationship between Design and Innovation in the experimental laboratories of the Bauhaus "... organise perceptions that become progressively confused due to the very fast transformation of the industrial society ..." (Borchardt-Hume, 2006; Fiedler, 2001; Molderings et al., 2009).

This concept is more than valid in our times where technological innovation is running faster than ever. 
Companies attempt to expand their markets, in which competition is becoming ever more global and therefore innovation represents a crucial strategic element that can contribute to success (Zelenika and Pearce, 2014).

The process stimulates the economy as a whole (Pearce et al., 2012; Pearce, 2012; Perez-Carmona, 2013): Innovation has been and still it is, the driving force propelling progress and economic growth. Innovation is developed within companies and it is based on the initiative and creativity of managers, designers, industrialists and investors. Equally, the development of environmental issues in manufacturing is becoming a critical component of international business activities (Shaker, 2015; Kahle and Gurel-Atay, 2013).

The success of many new industrial projects is based on the timely adoption of environmental approaches in company strategy, enabling the anticipation of restrictions introduced by standards and a general improvement in the management of environmental risks linked to industrial operations. Only companies with a substantial investment strategy for new product development will be able to take part in this market sector. In general terms, the redesign of products according to eco-compatibility criteria represents a quest for sustainable development.

An important indicator of this market trend consists of the formulation of the Dow Jones Sustainability Indices, which include all the most "sustainable" companies in each industrial sector. Therefore sustainable development is not incompatible with competitivity: Ecology, design and manufacturing are interdisciplinary areas, which together offer a notable potential for innovation.

\section{Innovation, Competitiveness and Sustainability: The Role of Designer}

The need for competitiveness and sustainability in the world, along with increasingly dynamic and complex scientific, industrial and cultural scenarios, require then a systemic approach in which research activities support the development of coherent, interconnected and ecoefficient industrial and social systems (Farah, 2015) responding to both market and social-cultural needs by:

- Recovering competitiveness in the research and industrial patent productivity

- Improving the quality of research and of industrial production in the industrial developing countries

- $\quad$ Promoting the transition from a resource-intensive to sustainable, knowledge-intensive materials and processes

Sustainability is the system's ability to survive by means of the optimal use of environmental resources (Magee et al., 2013). Taking our human evolution as an example, we can state that, at present, we are a race moving towards extinction, far faster than dinosaurs, because our systems of life and product manufacturing are not sustainable.

The designer has an important role in this scenario, because he is responsible for the definition of everyday objects. Any useful object (a medical device as well as a chair, table, car, ski, shoe or other) is based on design and design requires to conceptually work on materials, processing technology, visual effects and colour. The concept of maximize sustainability puts the designer into a difficult ethical situation: He has to decide which material or technology to use for every new application and so he is directly responsible for the increase in consumption of many non-renewable resources, either raw materials and energy while guaranty the commercial success of its product (Hazeltine and Bull, 1999; Akubue, 2011).

It is, therefore, important to examine aspects of processes and product, because the viewpoint offered by this type of approach considers all the factors connected to the creation of a sustainable product and not just its physical behaviour.

\section{Evolutionary Design through Innovation}

Knowledge of innovation and the principles governing it are key factors to the success and survival of the innovating entity (a new product or a service).

The literature fails in giving clear definition of innovation. Any research achievement by itself should not considered innovation in fact, even if researchers have speculated potential development for their inventions, only few may be considered true innovations (Cohen and Winn, 2007). It has to be recognising, indeed, that innovation could be driven by nontechnological factors such are creativity, design and new business models.

The difference between invention and innovation resides in the fact that the first can occur in a specific (scientific or industrial) environment, while innovation implies acceptance by the market and it is here that industrial design could play a critical role.

Though still often associated solely with aesthetics, the application of design is much broader and it is increasingly recognized as a key discipline to bring ideas to the market, transforming them into user-friendly and appealing products or services.

These basic concepts of competitiveness and sustainability could be strictly derived from Life evolution model. Life, which is the biological expression of sustainable growth, has developed by means of evolutional competition path between species generated by fortuitous mutations in a changing environment. As in Nature happens that not all mutations lead to success living entities, as it is in product design where not all 
research achievements give rise to product innovation (this is the reason why often the traditional approach to technology transfer fails in generating innovation).

From an evolutionary point of view, product innovation has to be considered like a living entity evolution where research achievements are equivalent to chaotic and stochastic mutations and that Chaos leads to Evolution as well as Creativity leads to Sustainable products as a result of a series of events and mutations that are generated during an adaptive design path.

A dynamical instability, a condition first exposed by Poincaré (1905) that mentions to an inherent lack of predictability in some physical systems.

But which creative and technological adaptive design process is involved in the identification of a sustainable product? Should we apply a systematic, as several design methods describe, or a more dynamic systemic approach?

\section{Systematic approach: The least complex systems are natural systems that are not organic, those that cybernetic call "trivial machines"; crystals, clouds, rivers, elementary particles and entire galaxies (lifeless) fall into this category, as well as all the artificial devices completely describable in terms of inputs/outputs. These systems do not show the least complex adaptive interactions with the environment; \\ Systemic approach: Complex systems (medium to high complexity) are all systems of the biosphere, from bacteria to the human population. Complex systems are adaptive and all of them are associated with the so- called emergent phenomena (life, mind, social organization, etc.). Complex systems in their evolutionary path are therefore always far from equilibrium and move in a space of infinite behavioural possibilities.}

\section{Results and Discussion}

Our theory is exploring through a systemic approach this novel area of innovation, in search of suitable solutions for new developments to be exploited for industrial applications, by facing constraints and opportunities for new technological developments using specific software tools to model reality (Artificial Intelligence) from structural to life cycle aspects, processing, visualization, marketing and others in an integrated design process testing their fitness (integrated design method).

The new concept underlined by our vision of Evolutionary design is the approach to research (for new material and technologies) and design development through their natural parallel adaptive evolution and selection, driven by the different aspects of the complex nature of sustainability.

Each year sees an ever-increasing number of researchers from diverse disciplines entering the field of Nano and advanced new materials and an increasing breadth of novel ideas and exciting new opportunities exploding on the international nanostructured material scene.

The intersections between these various disciplines are where much of the novel activity resides: Nanotechnologies, sustainable development and industrial design define a wide intersection area carrying great potential for the application of true innovations such as smart and multifunctional nanostructured materials, 3D metal printing industrial processes, structural colours and many others.

\section{Creativity and Innovation in the Evolutionary Design Approach}

If we consider living organisms, we see that they have developed according to functions to create complex systems, within which it is not an individual function that is privileged, but rather the entire system. Therefore, every component has to be correctly integrated within environment (our ecosystem): By ecosystem, we are not referring just on physical environment but to society itself where social development and economics are an inseparable part of it. Ecology, economy, design, marketing and manufacturing are interdisciplinary sectors that are not in mutual opposition: They offer a fertile terrain with notable development opportunities.

As we mentioned earlier, the combination of design with research in these fields can produce many ideas and innovations, particularly when ecology is more correctly intended in terms of sustainability. Most products designed today end up in the rubbish tip and this is a waste of raw materials and non-renewable energy sources: Often this fact is not considered or even recognised by the individuals responsible for this waste, namely manufacturers and designers. As the manufacturer's responsibility should extend beyond the moment of sale, right through to the disposal of an object, in the same way, the designer responsibility in his creative duty, should account that he is about to borrow valuable resources and it is influencing the environmental impact of its product in term of human lives lost and quality of life.

Designer should give careful consideration three elements:

- Materials: Often, excess material is used to correct errors of structure or form

- Shape: The shape may have to be modified following the use of a certain material or structure and as a result it may not be the original one 
- Structure: Structural elements or structural solutions may be added to correct problems in material or shape

Natural systems performing structural functions (a tree, the wings of a dragon fly, etc.) demonstrate a balance between these three elements, with a rational use of materials, minimizing the resources used (energy and materials). In order to manufacture something that is not just successful but also sustainable in environmental, social and cultural terms, we should mimic the processes that can be seen in nature's development of living organisms.

This is a process of system evolution where design is initially pure form and a moment of creation: The resulting form does not possess its own inherent logic or significance. Nature is rife in imagination and creativity, produced by the chaos and evolving mutations that generate millions of different living forms. The driving force behind the creation of new organisms and, on the part of the designer, new objects, is linked to the sustainable development of the system.

The creative process should begin with an unconstrained stage that defines the shape, expressing the designer's sensation of an object possessing a certain function: It continues with function refinement, developing an object that is the best possible at performing that function. This approach can be described as evolutionary design.

The evolutionary design process takes a spiral path, in which materials, forms and structure interact to evolve to a specific integrated solution under the driving force of a target function and the constrains of the specific scenario.

The material that is chosen (it could be one of the components of a complex system) is a part of the process linked to one or more functions so that not just one solution, but rather a whole series of design ideas, are combined.

In design, it is wrong to be obsessed with a single idea trying to develop it obstinately: This may result in a linear process where technological solutions are continuously added one over the other.

Designer should always work on a series of alternative ideas in order to be both creative and to end up with a successful and sustainable solution. Each of these alternatives, in the context of successive development stages, is subject to certain technical and contextual constrains.

Coming back to the parallel of life evolution, this evidence comes from the history of the origin of species. Consider the example of dinosaurs and mammals: Under certain unperturbed and stabilised conditions, the dinosaurs dominated the environment and, apparently, there were not successful alternative to them since evolution had moved in that direction in millions of years. Nature, however, did not extinguished all other forms of life that continued to evolve, even when their probabilities of survival were very small. But, when a perturbation occurred in the system, something of unexpected and highly improbable such as a big meteorite hitting our Planet may be, this occurrence has changed the surrounding conditions finally leading to the extinction of dinosaurs (that were characterized by a weakness in their thermal regulatory system) and to the flourishing of mammals that demonstrated to be able to survive in a wider range of environmental conditions.

Starting from this natural evolutionary example we can state that, when searching design innovations of complex systems, what is important is the balance of two conflicting goals: Exploiting good solutions and exploring the research space.

Mimicking mechanism of the natural
evolution, where a biological population
evolves over generations to adapt to an
environment by selection, crossover and
mutation, we should evaluate fitness of an
objective function value of a design candidate
and of design variables, during the creation
process itself (Apicella, 2008).

Namely, the designer may develop several ideas in the process of product design and, as the system becomes more specialised, a series of Artificial intelligence tools can be used to verify the strength of the design and its possibility of survival (integrated design).

Today everything can be readily simulated by Artificial Intelligence either car crash passenger behaviour or an outcome of an injection moulding process. This continuously improving the "in silico" human synthetic calculation capability shortens the decisional time for the evaluation of the robustness of a design idea (Apicella et al., 2010; Aversa et al., 2009; 2016a; 206b; 2016c; Sorrentino et al., 2009; Syed et al., 2016).

In this new scenario, the designer creative path is completely altered and includes the work in multidisciplinary team. The team's roles involve the evaluation of social aspects, technological factors, life cycle analysis for the determination of environmental impact and the calculation of structural performance.

The correct selection of materials requires an understanding of the relationships existing between structure and properties. Therefore, materials have to be used in a correct and appropriate way, in accordance with the natural characteristic of the material that can be exploited and enhanced.

How can such concepts be applied to the development of new products? The evolutionary approach to this 
problem (Fig. 1) makes it possible to achieve new features capable of improving the system as a whole.

An Evolutionary Design Biomedical Case Study: Biomechanics and Biomimetics to Foster advanced Materials and Technologies Potentials

Bone implants are expected to serve for much longer period or until lifetime without failure or revision surgery (Burnstein et al., 1976; Oh and Harris, 1976; Rohlmann et al., 1982; Reilly and Burstein 1974; Reilly and Burnestain, 1975). Thus, design and development of appropriate combination of material and prosthetic systems with high longevity and improved biocompatibility is highly essential (Ashman et al., 1984; Ashman and Rho 1988; Kummer, 1986;
Gottesman and Hashin, 1980; Annunziata et al., 2006; Dalstyra et al., 1993).

Figure 1 shows the design driven path for the combined material and product evolutionary development. This path is a combination of several combined research, industrial and theoretical activities (Fig. 2) such as biomimetic new hybrid ceramopolymeric material development (Schiraldi et al., 2004; Aversa et al., 2016a; 2016b; 2016c; Gramanzini et al., 2016) (Fig. 3), maximum exploitation of potentialities of the additive manufacturing in new production (Aversa et al., 2016a) (Fig. 4) and highly non-linear biofidel modeling of bone mechanical modeling, in silico, in vitro and in vivo tests (Fig. 5) (Aversa et al., 2009; Apicella et al., 2010).

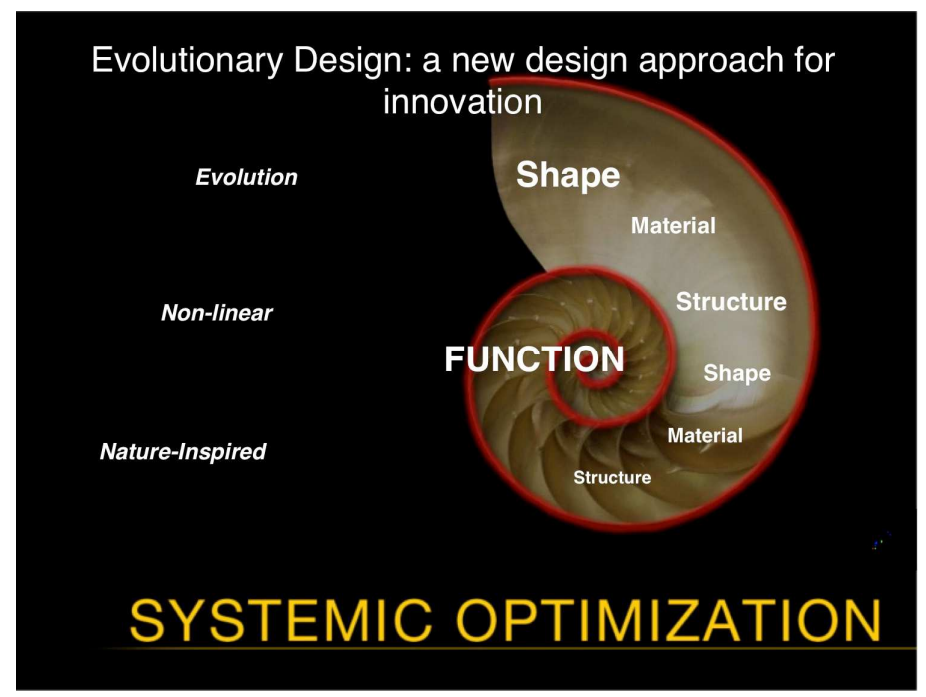

Fig. 1. Evolutionary design scheme

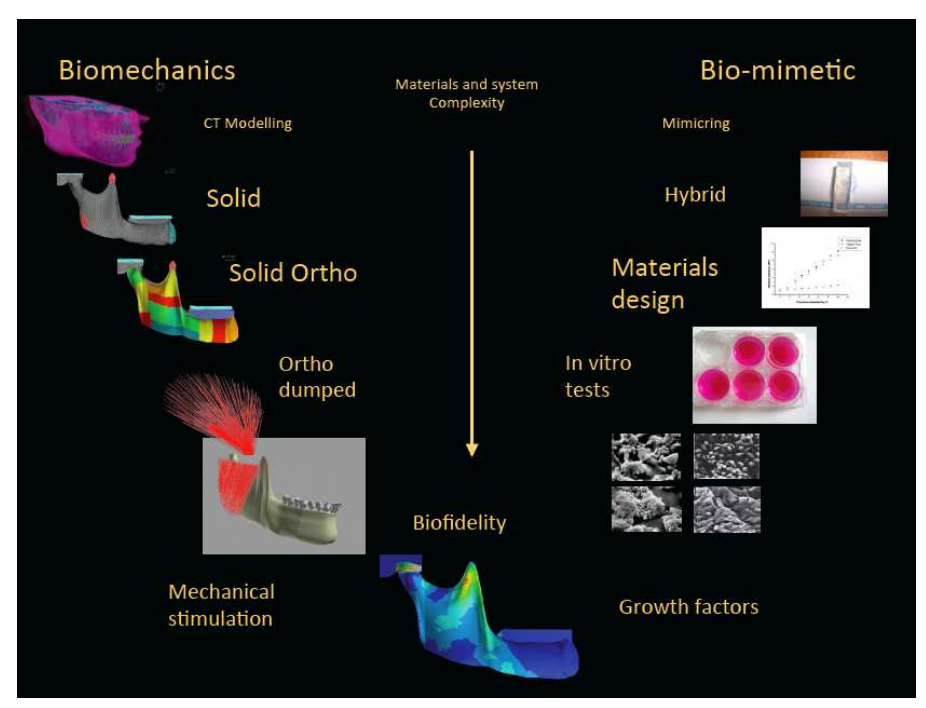

Fig. 2. Cooperative research development in the evolutionary design process in the field of biomedical prostheses 


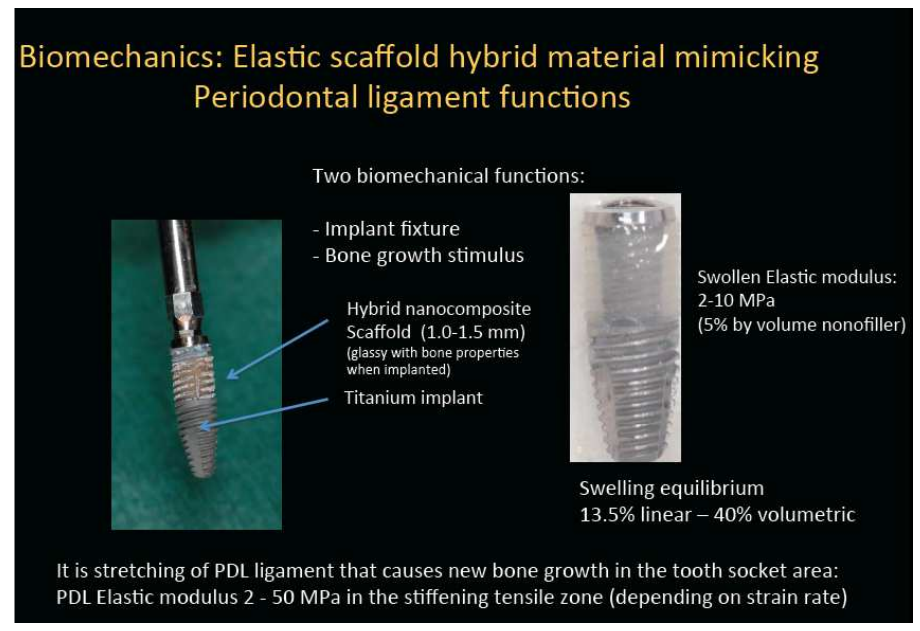

Fig. 3. Biomechanical functions of the new ceramo-polymeric hybrid nano-composites application in the development a new concept Titanium biomimetic dental implant (Aversa et al., 2016a)

\section{Biomimetic prostheses EBM production}
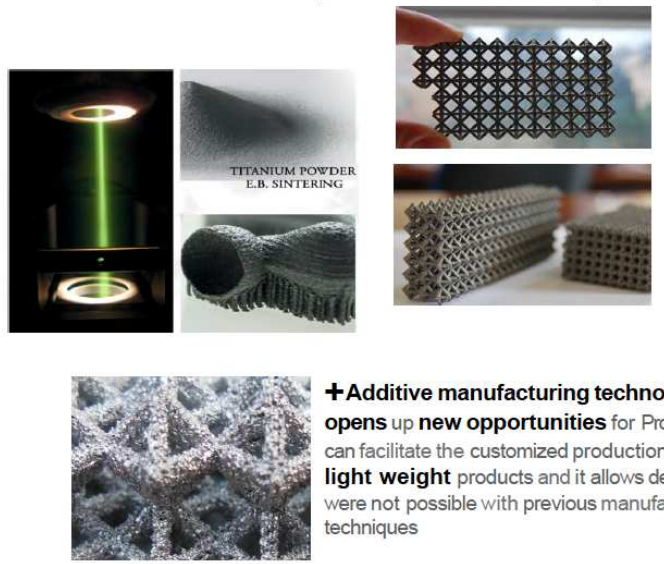

+Additive manufacturing technology

opens up new opportunities for Producers. It

can facilitate the customized production of strong

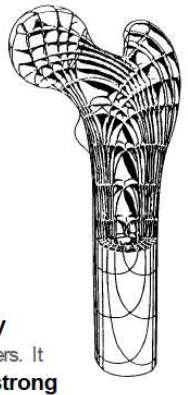

light weight products and it allows designs that

were not possible with previous manufacturing

techniques

Fig. 4. Integration and exploitation of the potentialities of the additive manufacturing into the new prostheses design

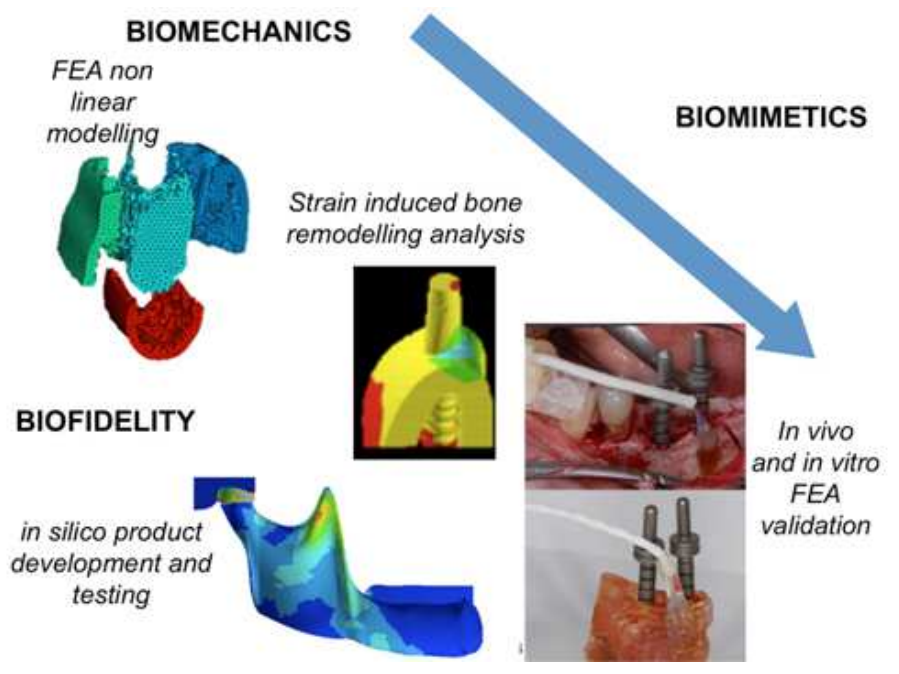

Fig. 5. Biomechanics, Biomimetic and Biofidelity cooperative path: An "in silico" tool for new prostheses design 


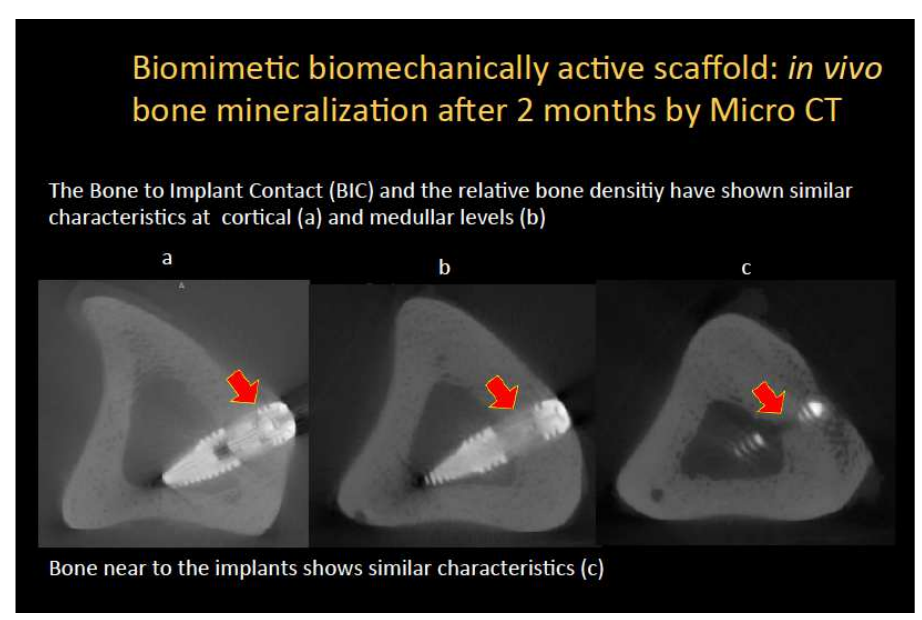

Fig. 6. Osteointegrative and osteinductive Biomimetic properties of hybrid ceramo-polymeric nanocomposites in in vivo osteointegration tests (Gramanzini et al., 2016)

If an implant fractures due to inadequate strength or mismatch in mechanical property between the bone and implant, then this is referred to as biomechanical incompatibility. The material replaced for bone is expected to have an "equivalent stiffness" (combination of material elastic modulus and prosthesis shape) matching that of bone area where it is implanted. The bone modulus varies in the magnitude from 4 to $30 \mathrm{GPa}$ depending on the type of the bone and the direction of measurement. The current implant materials which have higher stiffness than bone, strongly alters the physiological bone stress distribution and prevents the needed stress being transferred to adjacent bone, resulting in bone reabsorption around the implant and consequently to implant loosening (Sorrentino et al., 2007; Beaupre and Hayes, 1985; Carter and Hayes, 1977; Perillo et al., 2010).

This biomechanical incompatibility that leads to death of bone cells is called as "stress shielding effect". Thus, a customized material with excellent combination of high strength and stiffness matching that of the bone has to be used for biomechanical integrated implantation to avoid loosening of implants and higher service period to avoid revision surgery (Apicella et al., 2010; Aversa et al., 2016a; 2016b; 2016c).

The metal part of the new prosthesis will be made of titanium alloy using the Electron Beam Melting (EBM) technology.

This technology is based on the basic principle to melt thin layers of metal powder (about 70 microns) one after the other until the realization of the desired component.

The biological part of the project (hybrid ceramo polymeric material) aims to provide a new type of biocompatible and biodegradable material suitable for being formed into porous structures such as threedimensional scaffold (Petrescu et al., 2015).
The possible conjugation of biodegradable polyesters allows modulating the reabsorption time of the obtained hybrid composite materials by prolonging it with respect to the reabsorption time of the native collagen.

The layer of the new prosthesis that will be in contact with the bone tissue will be designed in order to increase the bone in growth inside the prosthesis to improve its encompassing into the bone (Fig. 6).

The new prosthesis should drastically reduce the wear phenomena and should provide a useful life in excess (more than 50\%) compared to traditional solutions, all resulting in a recovery of optimal functionality and improving the quality of life of the patient who sees drastically declining the risk of operation aiming at the replacement of worn prosthesis (revision).

The new type of biomimetic implants can find applications in orthopedics of knee, ankle, hip, shoulder and spine.

The innovative aspects reside in the fact that currently the prosthesis are designed for the replacement of a joint, damaged by different causes, but do not stimulate tissues regeneration. Also the average life of a prosthesis today is about $10 / 15$ years, while the new "biomimetic prosthesis" will have a longer life, estimated to be $20 / 25$ years. This aspect is very important because the average lifespan has increased significantly and this consequently increases the number of orthopedic surgery and social and health care related costs.

A further field of application of the product is surgical oncology to support and facilitate bone regeneration resulting in massive losses due to interventions of removal of both primitive and metastatic tumors. The prosthetic system might allow a better functional recovery by promoting bone recreation to ensure a good hold of the load, even going to impact on the quality of life of the individual patient, already seriously compromised by the basic oncological pathology. 
The concept of combining a metal support structure (to guarantee the resistance to the load) with a biomimetic scaffold (which promotes regeneration) finds replication in all those sectors of the therapeutic surgery involving the removal of bone and requiring a stimulation of the regeneration of resected tissue. In fact the concentrated bone marrow contains growth factors and mesenchymal stem cells that can specialize in:

- Bone cells

- Cartilage cells

- Tendon cells

\section{Conclusion}

As an example of the theoretical approach presented here, the Authors refer to a design driven innovation obtained through an evolutionary design combining previous research results of experimental activities carried out on prostheses and new fabrication processes based on Electron Beam Melting (EBM) additive technologies of Titanium powders and related advanced academic studies on biomechanics and biomimetics of implanted bones.

These activities have been taken up by the Authors in order to harvesting the hitherto untapped potential of such advanced materials and manufacturing technologies for the evolutionary design and fabrication of customized innovative "biomimetic prosthetic systems" that better integrate with the physiological biomechanics of the bones where they are implanted.

The achieved goal was the creation of added value by combination of existing research results with new necessary creative prosthesis design and modelling activities. The transfer of results across academic and industrial research on biomechanics and clinical studies, accelerated the innovation process and create profit while improving the quality of life of the patients with prostheses.

This project has opened and identified, through this evolutionary design, a number of new research activities addressed to foster the potential of the new technologies to enable new medical therapies contributing to personalised health care, to create and improve the technological basis and to increase the resource efficiency and reduce waste in the context of industrial and manufacturing processes.

Sustainability will be a theme in a long future in the world; this issue is particularly critical in emerging countries due to their rapid uncontrolled industrial growth. Main objective of the methodological approach is to create a public-private network that can support SMEs and consumers in adopting sustainable consumption and production practices and activities in the urban districts by promoting a conscious Sustainable
Design driven innovation educational campaign addressed to the consumption cycle stakeholders. Namely, new cleaner and sustainable approaches to product development, consumption patterns and behaviours will be achieved by combined educational and demonstrative actions targeted for the three main actors of the development-production-consumption chain:

- Product concept Developers, such as designers and SME's product development offices

- Producers such as single SME's and SME' category associations

- Consumers through Consumers associations and distributors

These key stakeholder groups should be involved in the understanding of the Design Driven Value Chain, that is the creation, management and distribution of value through the value chain and across industries.

An innovative, design-driven, sustainable approach in conceiving, developing, engineering and producing by using new greener materials and technologies can be effective in strengthening the competiveness and success of creative industries linked to manufacturing (e.g., industrial engineering, biomedical, architecture, automotive, art, crafts, supports for cultural items, decoration, fashion, furniture, lighting, interior design materials and products, jewels, luxury, media supports, publishing, sport and toys). This approach adds value to products and processes also by 'immaterial' factors (e.g., trend translation, enhanced sensations, values).

The biomimetic prostheses project specifically addressed the dissemination and spreading of innovative material and technology greener solutions for use in the biomedical creative industry sectors adopting sustainable and socially responsible approach to reduce energy consumption and environmental impact, conveys a holistic view of the industrial design process and emphasizes the following areas:

- Problem identification and analysis

- User-centred innovation (local social and cultural aspects)

- Concept development

- Emerging technologies and Strategic design

- Sustainable product development through life cycle analysis

\section{Acknowledgement}

This text was acknowledged and appreciated by Assoc. Pro. Taher M. Abu-Lebdeh, North Carolina A and T State Univesity, United States, Muftah H. El-Naas PhD MCIC FICCE QAFCO Chair Professor in Chemical Process Engineering Gas Processing Center College of 
Engineering Qatar University and (Ms.) Shweta Agarwala Senior Research Scientist at Singapore Center for 3D Printing Nanyang Technological University Singapore, whom we thanks and in this way.

\section{Funding Information}

This research has been funded by Italian Ministry of University and Research project FIRB Future in Research 2008 project RBFR08T83J.

\section{Author's Contributions}

All the authors contributed equally to prepare, develop and carry out this work.

\section{Ethics}

This article is original. Author declares that are not ethical issues that may arise after the publication of this manuscript.

\section{References}

Akubue, A., 2011. Appropriate technology for socioeconomic development in third world countries. J. Technol. Stud., 26: 33-43. DOI: 10.21061/jots.v26i1.a.6

Annunziata, M., R. Aversa, A. Apicella, A. Annunziata and D. Apicella et al., 2006. In vitro biological response to a light-cured composite when used for cementation of composite inlays. Dental Mater., 22: 1081-1085. DOI: 10.1016/j.dental.2005.08.009

Apicella, A., 2008. Scienza e Tecnologia dei Materiali: Approccio Biomimetico per un uso Sostenibile dei Materiali. 1st Edn., Giannini, ISBN-10: 887431390X, pp: 118.

Apicella, D., R. Aversa, V. Ferro, D. Ianniello and A. Apicella, 2010. The importance of cortical bone orthotropicity, maximum stiffness direction and thickness on the reliability of mandible numerical models. J. Biomed. Mater. Res., 93: 150-163. DOI: 10.1002/jbm.b.31569

Ashman, R.B. and J.Y. Rho, 1988. Elastic modulus of trabecular bone material. J. Biomechan., 21: 177-1781. DOI: 10.1016/0021-9290(88)90167-4

Ashman, R.B., S.C. Cowin, W.C. Van Buskirk and J.C. Rice, 1984. A continuous wave technique for the measurement of the elastic properties of cortical bone. J. Biomechan., 17: 349-361.

DOI: $10.1016 / 0021-9290(84) 90029-0$

Aversa, R., D. Apicella, L. Perillo, R. Sorrentino and F. Zarone et al., 2009. Non-linear elastic threedimensional finite element analysis on the effect of endocrown material rigidity on alveolar bone remodeling process. Dental Mater., 25: 678-690. DOI: $10.1016 /$ j.dental.2008.10.015
Aversa, R., R. Sorrentino and A. Apicella, 2016a. Biomechanically active ceramic-polymeric hybrid scaffolds for tissue engineering. Proceedings of the International Conference on Biological Sciences and Technology, (BST' 16), Atlantis Press, pp: 308-318. DOI: $10.2991 /$ bst-16.2016.46

Aversa, R., R.V.V. Petrescu, A. Antonio and F.IT. Petrescu, 2016b. Mitochondria are naturally micro robots-a review. Am. J. Eng. Applied Sci.

Aversa, R., R.V.V. Petrescu, A. Antonio and F.I.T. Petrescu, 2016c. Physiologic human fluids and swelling behavior of hydrophilic biocompatible hybrid ceramo-polymeric materials. Am. J. Eng. Applied Sci.

Beaupre, G.S. and W.C. Hayes, 1985. Finite element analysis of a three-dimensional open-celled model for trabecular bone. J. Biomech. Eng., 107: 249-56. DOI: $10.1115 / 1.3138550$

Borchardt-Hume, A., 2006. Albers and Moholy-Nagy: From the Bauhaus to the New World. 1st Edn., Yale University Press, New Haven, ISBN-10: 030012032X, pp: 190.

Burnstein, A., D.T. Reilly and M. Martens, 1976. Aging of bone tissue: Mechanical properties. J. Bone Joint Surgery, 58: 82-86. PMID: 1249116

Carter, D.R. and W.C. Hayes, 1977. The compressive behavior of bone as a two-phase porous structure. J. Bone Joint Surgery, 59A: 954-962. PMID: 561786

Cohen, B. and M.I. Winn, 2007. Market imperfections, opportunity and sustainable entrepreneurship. J. Bus. Ventur., 22: 29-49.

DO: 10.1016/j.jbusvent.2004.12.001

Dalstyra, M., R. Huiskes, A. Odgaard and L. Van Erning, 1993. Mechanical and textural properties of pelvic trabecular bone. J. Biomechan., 26: 349-361. DOI: 10.1016/0021-9290(93)90014-6

Farah, P.D., 2015. Sustainable energy investments and national security: Arbitration and negotiation issues. J. World Energy Law Bus., 8: 497-500. DOI: 10.1093/jwelb/jwv036

Fiedler, J., 2001. László Moholy-Nagy, Berlin.

Gottesman, T. and Z. Hashin, 1980. Analysis of viscoelastic behaviour of bones on the basis of microstructure. J. Biomechan., 13: 89-96. DOI: 10.1016/0021-9290(80)90182-7

Gramanzini, M., S. Gargiulo, F. Zarone, R. Megna and A. Apicella et al., 2016. Combined microcomputed tomography, biomechanical and histomorphometric analysis of the peri-implant bone: A pilot study in minipig model. Dental Mater., 32: 794-806.

DOI: 10.1016/j.dental.2016.03.025

Hazeltine, B. and C. Bull, 1999. Appropriate Technology: Tools, Choices and Implications. 1st Edn., Academic Press, New York, ISBN-10: 0123351901, pp: 364. 
Syed, J., N. Sahar, R. Aversa, R.V.V. Petrescu and D. Apicella et al., 2016. Periodontal bone substitutes application techniques and cost evaluation: A review. Am. J. Eng. Applied Sci.

DOI: $10.3844 /$ ofsp.10849

Kahle, L.R. and E. Gurel-Atay, 2013. Communicating Sustainability for the Green Economy. 1st Edn., M.E. Sharpe, New York, ISBN-10: 0765636832, pp: 312.

Kummer, B., 1986. Biomechanical principles of the statistics of the hip joint. A critical appraisal of a new theory. Zeitschrift fur Orthopadie und Ihre Grenzgebiete, 124: 179-187.

DOI: $10.1055 / \mathrm{s}-2008-1044544$

Magee, L., A. Scerri, P. James, J.A. Thom and L. Padgham et al., 2013. Reframing social sustainability reporting: Towards an engaged approach. Environ. Dev. Sustainability, 15: 225-243. DOI: $10.1007 / \mathrm{s} 10668-012-9384-2$

Molderings, H., R. Heyne and F.M. Neusüss, 2009. Moholy-Nagy. The Photograms. Catalogue Raisonné, Ostfildern.

Oh, I. and W.H. Harris, 1976. Proximal strain distribution in the loaded femur. An in vitro comparison of the distributions in the intact femur and after insertion of different hip-replacement femoral components. J. Bone Joint Surgery, 60: 75-85. PMID: 624762

Pearce, J., S. Albritton, G. Grant, G. Steed and I. Zelenika, 2012. A new model for enabling innovation in appropriate technology for sustainable development. Sustainability: Sci. Pract. Policy, 8: 42-53.

Pearce, J.M., 2012. The case for open source appropriate technology. Environ. Dev. Sustainability, 14: 425-431. DOI: $10.1007 / \mathrm{s} 10668-012-9337-9$

Perez-Carmona, A., 2013. Growth: A Discussion of the Margins of Economic and Ecological Thought. In: Transgovernance: Advancing Sustainability Governance, Meuleman, L. (Ed.), Springer, Heidelberg, pp: 83-161.

Perillo, L., R. Sorrentino, D. Apicella, A. Quaranta and. E. Gherlone et al., 2010. Nonlinear visco-elastic finite element analysis of porcelain veneers: A submodelling approach to strain and stress distributions in adhesive and resin cement. J. Adhesive Dent., 12: 403-413.

Petrescu, F.1., E. Buzea, L. Nănuţ, M. Neacşa and C. Nan, 2015. The role of antioxidants in slowing aging of skin in a human. Analele Universitatii Din Craiova Biologie Horticultura Tehnologia Prelucrarii Produselor Agricole Ingineria Mediului, 20: 567-574.

Poincaré, H., 1905. Sur la dynamique de l'électron, in Comptes Rendus.
Reilly, D. and A.H. Burstein, 1974. The mechanical properties of cortical bone. J. Bone Joint Surgery, 56: 1001-1021.

Reilly, D.T. and A.H. Burnestain, 1975. The elastic and ultimate properties of compact bone tissue. J. Biomechan., 8: 393-405. DOI: $10.1016 / 0021-9290(75) 90075-5$

Rohlmann, A., U. Mossner, G. Bergmann and R. Kolbel, 1982. Finite-element-analysis and experimental investigation of stresses in a femur. J. Biomed. Eng., 4: 241-246. DOI: 10.1016/0141-5425(82)90009-7

Schiraldi, C., A. D’Agostino, A. Oliva, F. Flamma and A. De Rosa et al., 2004. Development of hybrid materials based on hydroxyethylmethacrylate as supports for improving cell adhesion and proliferation. Biomaterials, 25: 3645-3653. DOI: $10.1016 /$ j.biomaterials.2003.10.059

Shaker, R.R., 2015. The spatial distribution of development in Europe and its underlying sustainability correlations. Applied Geography, 63: 304-314. DOI: 10.1016/j.apgeog.2015.07.009

Sorrentino, R., D. Apicella, C. Riccio, E.D. Gherlone and F. Zarone et al., 2009. Nonlinear visco-elastic finite element analysis of different porcelain veneers configuration. J. Biomed. Mater. Res., 91: 727-736. DOI: $10.1002 / \mathrm{jbm} . b .31449$

Sorrentino, R., R. Aversa, V. Ferro, T. Auriemma and F. Zarone et al., 2007. Three-dimensional finite element analysis of strain and stress distributions in endodontically treated maxillary central incisors restored with diferent post, core and crown materials. Dent Mater., 23: 983-993. DOI: $10.1016 /$ j.dental.2006.08.006

Zelenika, I. and J.M. Pearce, 2014. Innovation through collaboration: Scaling up solutions for sustainable development. Environ. Dev. Sustainability, 16: 1299-1316 DOI: 10.1007/s10668-014-9528-7 